\title{
ANALYSIS OF THE MECHANICAL PROPERTIES OF WOOD-PLASTIC COMPOSITES BASED ON AGRICULTURE CHILI PEPPER WASTE
}

\author{
Delia Julieta Valles-Rosales ${ }^{1, \star}$, Luis Alberto Rodríguez-Picón ${ }^{2}$, Luis Carlos Méndez-González ${ }^{3}$, \\ Arturo del Valle-Carrasco ${ }^{4}$,Haytham Alodan
}

\begin{abstract}
In this study, a new composite material conception based on polypropylene (PP) and wood particles obtained from agricultural waste was investigated. Specifically, stalks and leafs of chili plants of the region of New Mexico, Texas, USA were used as a plant-based reinforcing material. For this, a design of experiments (DOE) is proposed considering different percentages of PP, wood, fire retardant, coupling agent and UV stabilizer, different mesh sizes are also considered. Samples were obtained using an extrusion molding machine. A statistical analysis is proposed to obtain the optimal percentages of the components considered in the fabrication of the samples in order to enhance the mechanical and morphologic properties of this new composite. Results show that the yield stress, breaking stress and ultimate tensile stress can be maximized with a proportion of 3 to $1(63,75 \%$ PP and $21,25 \%$ wood fiber) of PP and wood fiber.
\end{abstract}

Keywords: Chili leafs, chili stalks, mechanical properties, polypropylene, wood plastic composite.

\section{INTRODUCTION}

Commodity plastics (i.e., polyethylene and polypropylene) have took over some conventional materials in different areas due to their many advantages, such as low cost, ease to process, the ability to be mass-produced, and their versatility (Georgopoulos et al. 2005). Limited properties of plastics narrow their applications. This, lead researchers and inventors to work on modified plastics with different techniques and materials to raise up the properties to acceptable levels that can be used in wide range of applications. (Georgopoulos et al. 2005, Dányádi et al. 2007, Ho et al. 2011).

As a result, composites components, wood and plastics, can be modified chemically by different treatments (Dányádi et al. 2010, Hietala et al. 2011) or physically by adding additives to cover the gap of certain properties that do not match with the applications constraints for example, material strength.

\footnotetext{
${ }^{1}$ Associate Professor, Department of Industrial Engineering, MSC 4230/ECIII, Rm 288. New Mexico State University. Las Cruces, New Mexico. USA

${ }^{2}$ Research Professor, Department of Industrial Engineering, Autonomous University of Ciudad Juárez - University City, Cd. Juárez, Chihuahua México.luis.picon@uacj.mx.

${ }^{3}$ Research Professor, Department of Industrial Engineering and Manufacturing, Autonomous University of Ciudad Juárez, Chihuahua, Mexico. luis.mendez@uacj.mx.

${ }^{4}$ College Instructor, Graduate School, New Mexico State University, Las Cruces, New Mexico State University. Las Cruces, New Mexico. USA arturodelvalle@me.com.

${ }^{5}$ Manager of the National Center for Industrial Development, Assistant Research Professor of Industrial Engineering, King Abdulaziz City for Science and Technology (KACST), Riyadh, Saudi Arabia. halodan@kacst.edu.sa

"Corresponding author: dvalles@nmsu.edu
}

Received: 26.11.2014 Accepted: 03.10.2015 
One of the more important and innovative composite materials are the wood plastic components (WPC), which are novel materials made of plant biomass and polymer blends that exhibit useful properties which surpass those of the individual components, and are predicted to play important roles in sustainable markets. Many researchers have previously worked WPC using a variety of polymer matrices, coupling agents, biological additives and UV stabilizers among other possible ingredients. For example, Wechsler and Hiziroglu 2007, investigated the mechanical properties of WPCs by creating specimens having $60 \%$ and $80 \%$ particle and fiber of radiata pine (Pinus radiata) mixed with PP and four different additives: Structor TR 016 which is a coupling agent, CIBA an anti-microbial agent, IRGAGUARD F3510 a fungicide and CIBA UV which is a filter coating; and they discovered that both chemical and physical properties of samples were improved by around $38 \%$ with the addition of the four chemicals into panels.

Different varieties of cellulosic materials have been investigated for the design of WPCs, for example Wang et al. (2008), studied the stability and mechanical properties of bamboo-plastic composites using virgin PVC and bamboo granule as a filler taking into account variations on moisture content, granular size of bamboo particles and proportions. They found out that an increase in the content of PVC will improve the mechanical properties of the sample, furthermore they concluded that an optimum granule size of bamboo is 40 mesh and that a $50 \%$ of bamboo resulted in the best tensile strength. It also has to be emphasized that the majority of research on WPC implies the use of biomass, specifically cellulosic which is result of plant waste. Research conducted by Ayrilmis et al. (2010), considers pine cone waste used as a principal component along with wood flour and found that adding a $10 \%$ wt of cone flour increased the flexural properties of the composite compared to a wood flour PP only mixture. Fabiyi et al. (2010), then explored different woods in order to determine whether there was a dependence in the use of a diverse selection of wood as an ingredient of WPCs composed with High Density Polyethylene (HDPE); the selection of woods were poplar, Douglas-fir, black locust, white oak, and ponderosa pine and it was determined that thermal stability and mechanical properties of WPCs was wood species dependent and in particular the best option for species among the selected was the hybrid Poplá, Moreno et al. (2013), studied the properties of WPC reinforced by foams and found out that by incorporating the foam agent the properties of the mechanical composite decreased slightly. Ozdemir et al. (2014), investigated the case where the wood composite is immersed in hot and cold water and the effects that this has on the thickness swelling and the water absorption of the WPC.

However, due to the global demand and environmental awareness, the use of plant waste materials has increased. Nourbakhsh and Ashori (2010), investigated the use of corn stalk, reed stalk and oilseed stalk in combination with thermoplastics and concluded that with addition of agro-waste materials, tensile and flexural properties of the composites are significantly enhanced. Reis (2011), supplemented these findings by also studying the mechanical properties of composites with the use of agro-waste materials. The effect of cork and rice husk ash fillers on the mechanical properties of polyester based composites was investigated and it was concluded that the use of agro-waste materials increased flexural strength and decreased fractural toughness which represented an improvement in the properties of the polyester matrix. Additional research has been conducted considering the use of recycled polymer matrices. Yeh et al. (2009), compounded acrylonitrile butadiene styrene (ABS) with 50\%wt wood particles; both virgin resin and polymer recovered from computer monitors were utilized and it was determined that the mechanical properties of ABS with wood reinforcement remained unchanged when the virgin $\mathrm{ABS}$ in the matrix is replaced by recycled ABS. This supports the concept that recycled plastics can also be used, which would lower the footprint of plastic production. Another important concept explored was made by García et al. (2009), who investigated the addition of fire retardants in WPC by using HDPE. Their results showed that addition of wood fibers increased the mechanical properties (tensile, flexural and compression) of the composite. Also, the addition of fire retardant was used to add auto-extinguishing materials and it showed as well that it lower the fading of the material when exposed to the outdoors.

When designing a WPC it would be advantageous and more environmentally conscious to obtain a composite that uses agro-waste material combined with a recycled polymer matrix which preserves valuable mechanical properties and which possesses auto-extinguishing materials. The purpose of this article is to maximize the mechanical properties of such composite. 
Chili pepper is an annual plant in the region of New Mexico. In 2000, 19000 chili pepper acres were harvested in New Mexico (NMDA 1994-2000) yielding 80500 tons of green chili and cayenne peppers and 18500 tons of red chili peppers. After harvesting, the stalks and roots from the chili plant are of no economic value in any industry, therefore it would be desirable to find an innovative and sensible use to the remains of the plants that could reduce the impact of current high-polluting processes. This study focuses on a new WPC based on pre-dried New Mexico's red chili stems and leafs combined with PP. Mixtures of chili stem waste of two particle sizes, 30 and 80 meshes, plastics, PP, as well as different amounts of additives including MAPP as a coupling agent, fire retardants, UV stabilizers to enhance the compatibilization and sun light resistance respectively were produced using an injection molding machine in different load percentages. This research studies the effect of these material combinations and particle size on the mechanical and morphologic properties of this new composite.

\section{MATERIALS AND METHODS}

\section{Materials}

Chili pepper waste was collected from a local chili processing company. The total yield resulted in three bales with a combined weight of $37,78 \mathrm{~kg}$. Table 1 shows the constituents of the chili wastes stems.

Table 1. Percentage constituents of chili pepper stems.

\begin{tabular}{|ccccccc|}
\hline & Lignin & $\begin{array}{l}\text { Cellulose } \\
(\text { Glucose })\end{array}$ & $\begin{array}{l}\text { Hemicellulose } \\
\text { (xylose) }\end{array}$ & Holocellulose & Ash & $\begin{array}{l}\text { Extractives } \\
\text { (wax) }\end{array}$ \\
\hline $\begin{array}{c}\text { Composition } \\
(\%)\end{array}$ & 27,8 & 45,1 & 26,1 & 78,7 & 5,8 & 2,49 \\
\hline
\end{tabular}

Using hummer mill (Thomas Whiley Grinding Machine Model \#4), chili stems fibers were grounded in particles. These particles were classified by screening machine (Shaker machine, Ro-Tap, Model \# T672, Tyler Industrial Products) into two mesh sizes, 30 and 80, and dried to $4 \%$ of moisture content. Polymer used is a virgin Injection molding grade PP. Additives used were MAPP supplied by Chemtura Co.(POLYBOND@3200, density 0,91 g/cc, melt flow index $115 \mathrm{~g} / 10 \mathrm{~min}$, melting point $157^{\circ} \mathrm{C}$ ) used as interfacial enhancement agent. In addition, LOWILTE@19, (flash point $278^{\circ} \mathrm{C}$, Ignition temperature $330^{\circ} \mathrm{C}$, melting point range $115-150^{\circ} \mathrm{C}$, thermal decomposition $350^{\circ} \mathrm{C}$ ) is used as a light stabilizer supplied by Chemtura Co. Moreover, Non-halogenated flame retardant JJAZZ @, (JJAZZ SP1; melting point $>250^{\circ} \mathrm{C}$, specific gravity $1,3-1,35$ ) supplied by JJI Technologies was used to stabilize the material during processing and to reduce the fibers heat degradation. Materials were preheated for better mixing. WPC composite combinations were produced according to ASTM 638-03 standard, as can be seen in Figure 1, using a plunger injection molding machine.

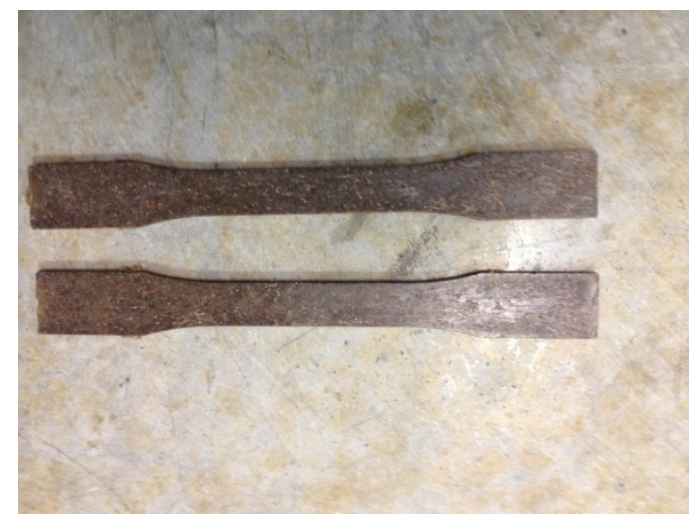

Figure 1. WPC sample test according to ASTM 638-03. 


\section{METHODS}

Chili stems wastes particles, PP polymer, MAPP coupling agent, UV stabilizer, fire retardant agent were mixed together manually according to the DOE in Table 2, considering 300 grams of total weight for each combination.

Table 2. DOE for the WPC Formulations.

\begin{tabular}{|c|c|c|c|c|c|}
\hline No & Combination & Fire Retardant \% & Coupling Agent $\%$ & UV Stabilizer\% & Mesh Size \\
\hline 1 & 1 & 11,25 & 3,75 & 0 & 30 \\
\hline 2 & 1 & 7,5 & 7,5 & 0 & 30 \\
\hline 3 & 1 & 7,5 & 3,75 & 3,75 & 30 \\
\hline 4 & 2 & 11,25 & 3,75 & 0 & 30 \\
\hline 5 & 2 & 7,5 & 7,5 & 0 & 30 \\
\hline 6 & 2 & 7,5 & 3,75 & 3,75 & 30 \\
\hline 7 & 1 & 11,25 & 3,75 & 0 & 80 \\
\hline 8 & 1 & 7,5 & 7,5 & 0 & 80 \\
\hline 9 & 1 & 7,5 & 3,75 & 3,75 & 80 \\
\hline 10 & 2 & 11,25 & 3,75 & 0 & 80 \\
\hline 11 & 2 & 7,5 & 7,5 & 0 & 80 \\
\hline 12 & 2 & 7,5 & 3,75 & 3,75 & 80 \\
\hline
\end{tabular}

Where, combination 1 implies $42,5 \%$ of PP and $42,5 \%$ of chili steam wastes, combination 2 is $63,75 \% \mathrm{PP}$ and $21,25 \%$ of chili steam wastes.

Chili stems wastes particles were put in an oven for $24 \mathrm{~h}$ at $80^{\circ} \mathrm{C}$ in order to reduce the moisture content from $10 \%$ to $4 \%$. After that, mixtures were heated under manual continuous heating for 15 min. at $121^{\circ} \mathrm{C}$ before palletizing. Then the combinations were produced in specimens (according to ASTM D638-03) using experimental plunger injection molding machine (IM plunger type Industrial Plastic Cender Co., Model T9013-P). Molding machine set-up was defined as follows: barrel and nozzle temperature at $182^{\circ} \mathrm{C}$, injection pressure $6895 \mathrm{kPa}$, mold temperature $80^{\circ} \mathrm{C}$ and injection time $30 \mathrm{~s}$.

Samples obtained were subjected to Tension test, flexural bending test, and charpy impact resistance test (see, ASTM D638-03, ASTM D790-03 and ASTM D6110-06). These tests were conducted to analyze the effects of material compositions and grains sizes on yield stress, ultimate tensile stress, breaking stress and modulus of elasticity.

\section{Statistical Analysis}

The results were analyzed using a MANOVA considering every response variable (yield stress ( $2 \%$ offset, $\mathrm{MPa}$ ), ultimate tensile stress (MPa), breaking stress (MPa), modulus of elasticity (MPa)), obtained from the mechanical tests. The best percentages of the components $(\%$ of PP, $\%$ of wood, $\%$ of fire retardant, $\%$ of the coupling agent, $\%$ of the UV stabilizer and mesh size) were determined and an optimized set of levels for these factors was established. 


\section{RESULTS AND DISCUSSION}

In Table 3, the results obtained from the mechanical tests applied to the specimens defined in the DOE are presented. In first instance, these results were analyzed using a MANOVA in order to determine which responses have significant differences between the levels of the factors; a summary of the test statistics and the p-values of the MANOVA is presented in Table 4.

Table 3. Results of the mechanical tests for the WPC specimens.

\begin{tabular}{|c|c|c|c|c|}
\hline Formulation \# & $\begin{array}{c}\text { Yield Stress (2\% } \\
\text { Offset)(MPa) }\end{array}$ & $\begin{array}{c}\text { Ultimate } \\
\text { Tensile Stress } \\
(\mathrm{MPa})\end{array}$ & $\begin{array}{l}\text { Breaking } \\
\text { Stress } \\
(\mathrm{MPa})\end{array}$ & $\mathrm{MOE}(\mathrm{MPa})$ \\
\hline 1 & 6,7 & 11,9 & 10,3 & 18,9 \\
\hline 2 & 9 & 15 & 15 & 28,9 \\
\hline 3 & 7,5 & 16,2 & 16,2 & 25,5 \\
\hline 4 & 12 & 21,3 & 18,9 & 29,2 \\
\hline 5 & 10 & 22,9 & 22 & 24,9 \\
\hline 6 & 9,2 & 24,1 & 22,9 & 24 \\
\hline 7 & 9,7 & 16,8 & 16,7 & 36,8 \\
\hline 8 & 6,1 & 17,1 & 17 & 43,9 \\
\hline 7 & 12,9 & 22,8 & 22,7 & 59,3 \\
\hline 8 & 7,3 & 21,4 & 20,6 & 29,4 \\
\hline 9 & 9,2 & 21,9 & 21 & 23,6 \\
\hline 10 & 10,3 & 26,2 & 25,8 & 32,8 \\
\hline
\end{tabular}

Table 4. MANOVA results of the WPC mechanical tests.

\begin{tabular}{|clccc|}
\hline Constituent & Criterion & Test Statistic & F & P-Value \\
\hline \multirow{3}{*}{ Combination } & Wilks' & 0,00845 & 117,394 & 0 \\
& Lawley-Hotelling & 117,39448 & 117,394 & 0 \\
& Pillai's & 0,99155 & 117,394 & 0 \\
\hline \multirow{3}{*}{ Fire Retardant } & Wilks' & 0,08269 & 11,093 & 0,019 \\
& Lawley-Hotelling & 11,09349 & 11,093 & 0,019 \\
& Pillai's & 0,91731 & 11,093 & 0,019 \\
\hline \multirow{3}{*}{ Coupling Agent } & Wilks' & 0,15539 & 5,436 & 0,065 \\
& Lawley-Hotelling & 5,43559 & 5,436 & 0,065 \\
& Pillai's & 0,84461 & 5,436 & 0,065 \\
\hline \multirow{3}{*}{ UV Stabilizer } & Wilks' & 0,69524 & 0,767 & 0,579 \\
& Lawley-Hotelling & 0,43836 & 0,767 & 0,579 \\
& Pillai's & 0,30476 & 0,767 & 0,579 \\
\hline \multirow{2}{*}{ Mesh Size } & Wilks' & 0,26138 & 2,826 & 0,169 \\
& Lawley-Hotelling & 2,8259 & 2,826 & 0,169 \\
& Pillai's & 0,73862 & 2,826 & 0,169 \\
\hline
\end{tabular}


From Table 4, it can be noted that coupling agent, UV stabilizer and mesh size are not significant, considering a significance level of 5\%. On the other hand, the P-Values obtained for the combination and fire retardant factors suggest that we must fail to reject the null hypothesis that all statistical means are the same. Hence, we can conclude that combinations and fire retardant percentages will make a difference on the yield stress, ultimate tensile strength, breaking stress and modulus of elasticity for this particular experiment. However, we can see that the P-values for the mesh size, UV stabilizer and coupling agent are 0,$16 ; 0,579$ and 0,065 which raises a suspicion that these factors do not have an influence on the response variables.

In Figures 2, 3, 4 and 5 the main effect plots for every response variable are presented.

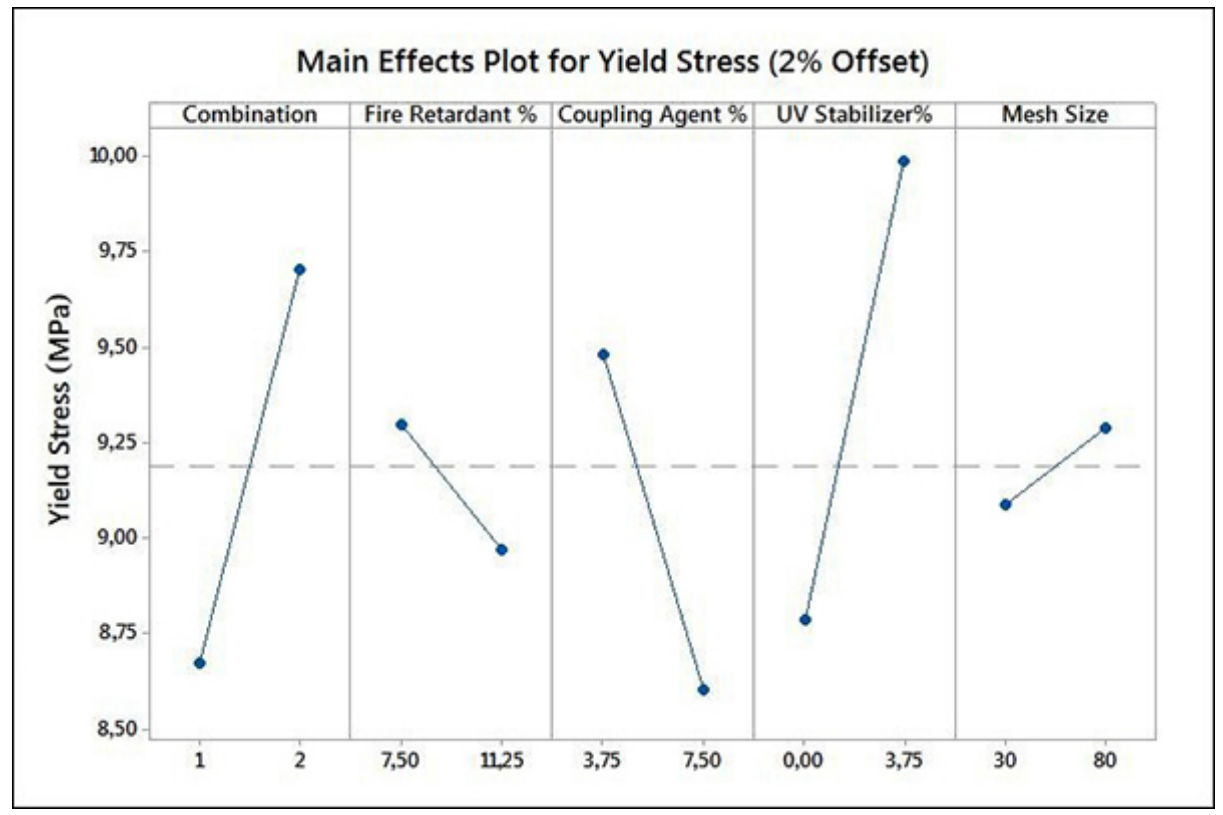

Figure 2. Main effects for yield stress for the various WPC formulations.

The main objective is to maximize each one of the mechanical properties of the WPC. For the Yield Stress, best levels of the factors are a combination of $63,75 \%$ PP and $21,25 \%$ of wood, $7,5 \%$ fire retardant; $3,75 \%$ coupling agent; $3,75 \%$ UV stabilizer and 80 mesh size.

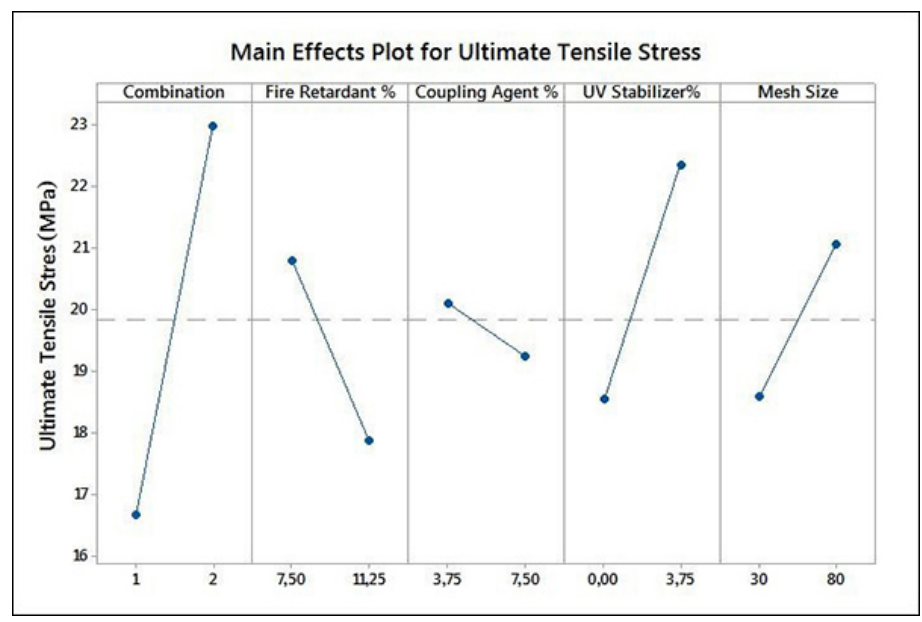

Figure 3. Main effects for ultimate tensile stress for the various WPC formulations. 
For the ultimate tensile stress, the best levels of the factors are, a combination of $63,75 \%$ PP and $21,25 \%$ of wood; $7,5 \%$ fire retardant; $3,75 \%$ coupling agent; $3,75 \%$ UV stabilizer and 80 mesh size.

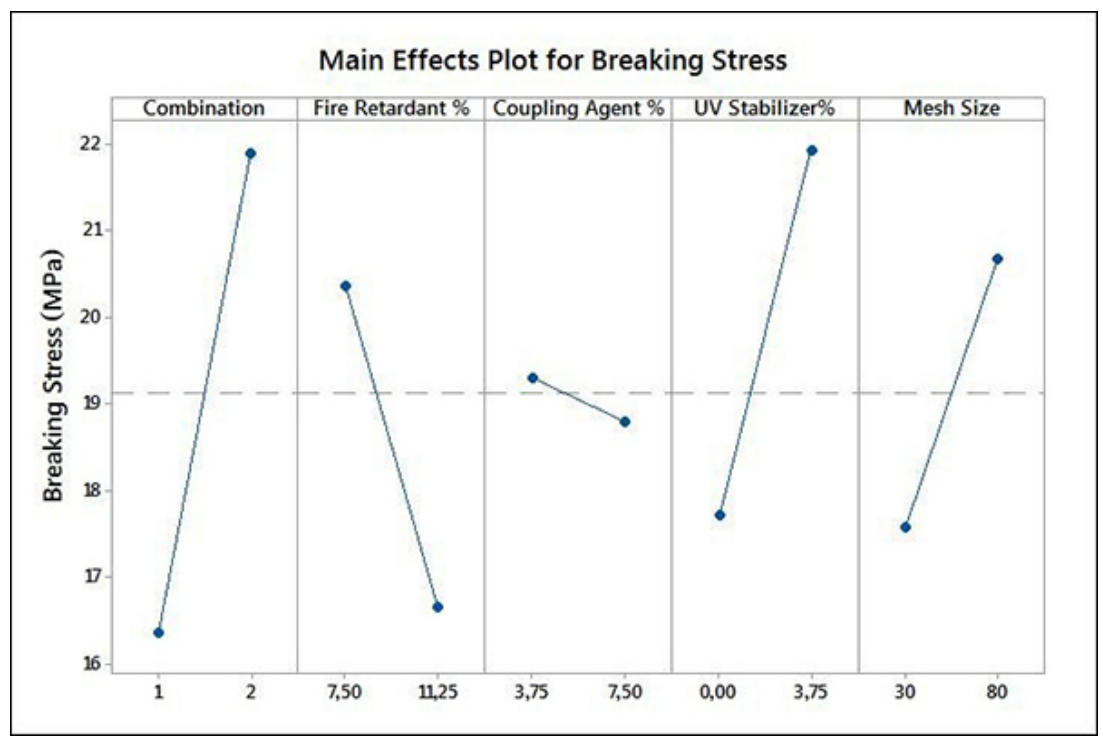

Figure 4. Main effects for breaking stress for the various WPC formulations.

For the breaking stress, best levels of the factors are a combination of $63,75 \%$ PP and $21,25 \%$ of wood; 7,5\% fire retardant; $3,75 \%$ coupling agent; 3,75\% UV stabilizer and 80 mesh size.

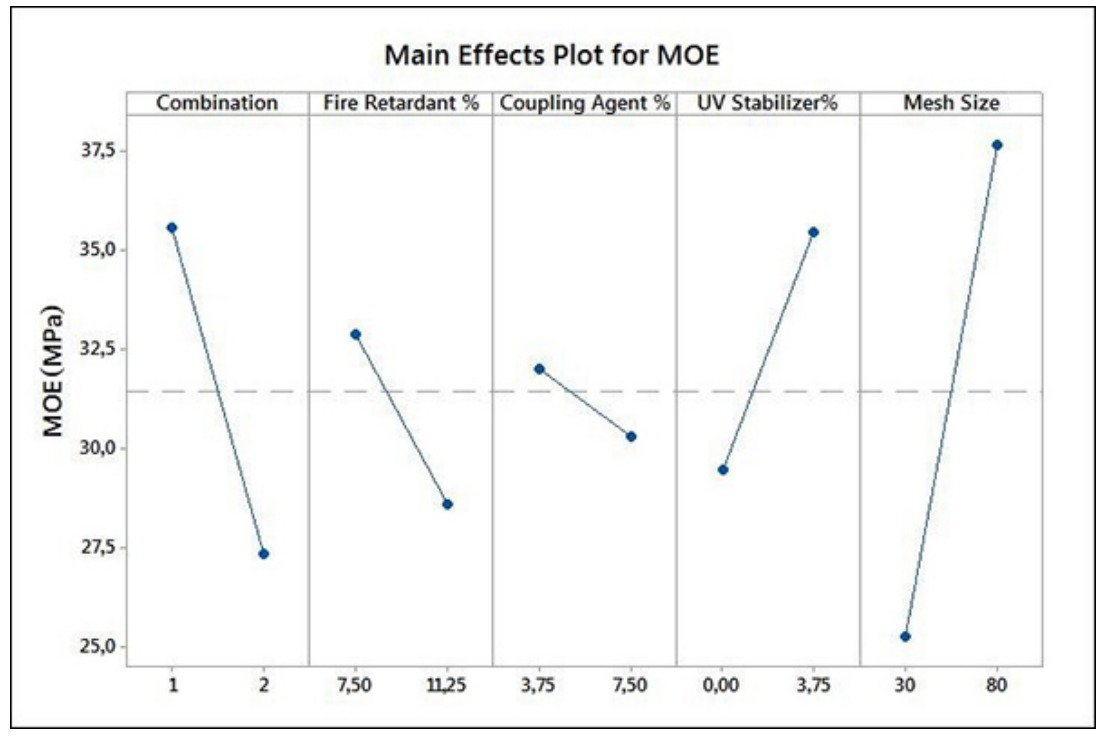

Figure 5. Main effects for modulus of elasticity for the various WPC formulations.

For the modulus of elasticity, best levels of the factors are a combination of $42,5 \% \mathrm{PP}$ and $42,5 \%$ of wood; 7,5\% fire retardant; 3,75\% coupling agent; 3,75\% UV stabilizer and 80 mesh size. 
In order to maximize the yield stress, ultimate tensile strength and breaking stress the best levels are $63,75 \%$ PP and $21,25 \%$ of wood (which implies a proportion of 3 to 1 of the PP and the wood composite); $7,5 \%$ fire retardant; $3,75 \%$ coupling agent; $3,75 \%$ UV stabilizer and 80 mesh size. In the case of the modulus of elasticity, the only difference is the proportion of the PP and the wood composite, in this case it must be considered to be 1 to 1 .

\section{Morphology Characteristics}

Scanning electron microscopy (SEM) was used to analyze the interaction of the materials and the chili stems particle size in a microscopic scale. Fracture surface of the tension test specimens of all material combinations developed by the DOE were scanned. From Figure 6, it can be noticed that 80 mesh sizes (right) mixed better than 30 mesh size (left). In addition, there are less voids in samples with 80 mesh than 30 mesh. Moreover, in 80 mesh sizes it is noticeable that the fibers broke along the axis of the fibers; meanwhile the 30 mesh size sample composites were pulled out from the matrix. We believe that this is due to the better mixing between the matrix and the fibers along with the presence of the coupling agents, which provided good interaction between the polymer matrix and the fibers. Furthermore, material combinations play a big role in the morphology of the composite material. From Figure 7 it can be noticed that increasing the percentage of PP reduced the voids within the material. In addition, plastic tends to form layers of materials. The fracture surface of the left image shows that plastic pulled out; meanwhile the right image with higher percentage of PP is broke as layer. We believe that more PP provided better environment for mixing and packing of the material. Confocal images in figures 8 and 9 confirm what SEM images showed.

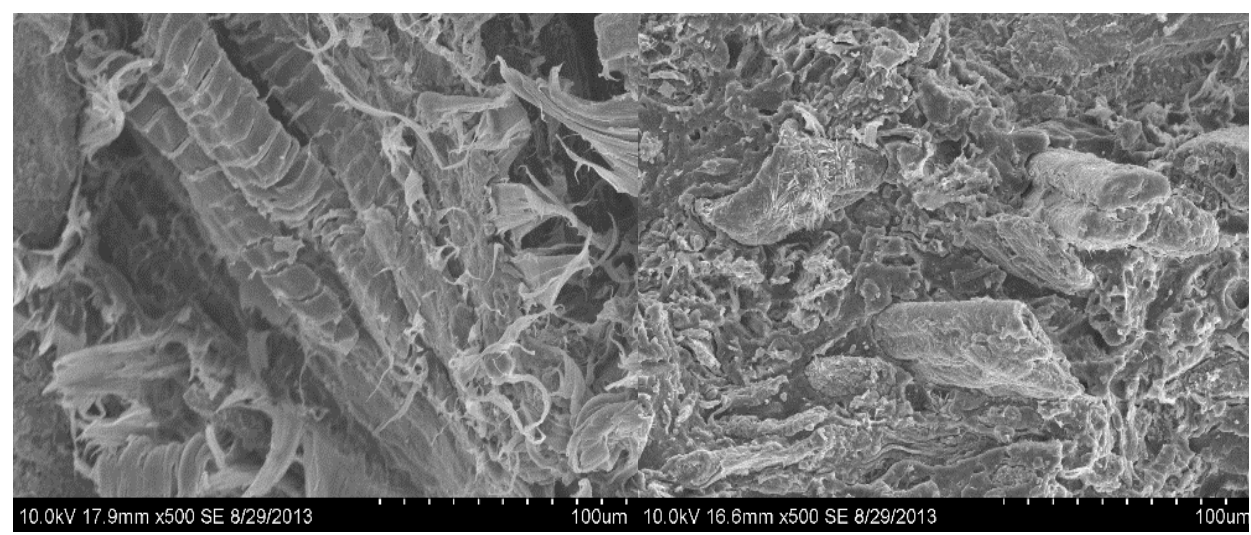

Figure 6. SEM images: left combination (1) 30 mesh size, right combination (7) 80 mesh size (both samples has the same material compositions). 


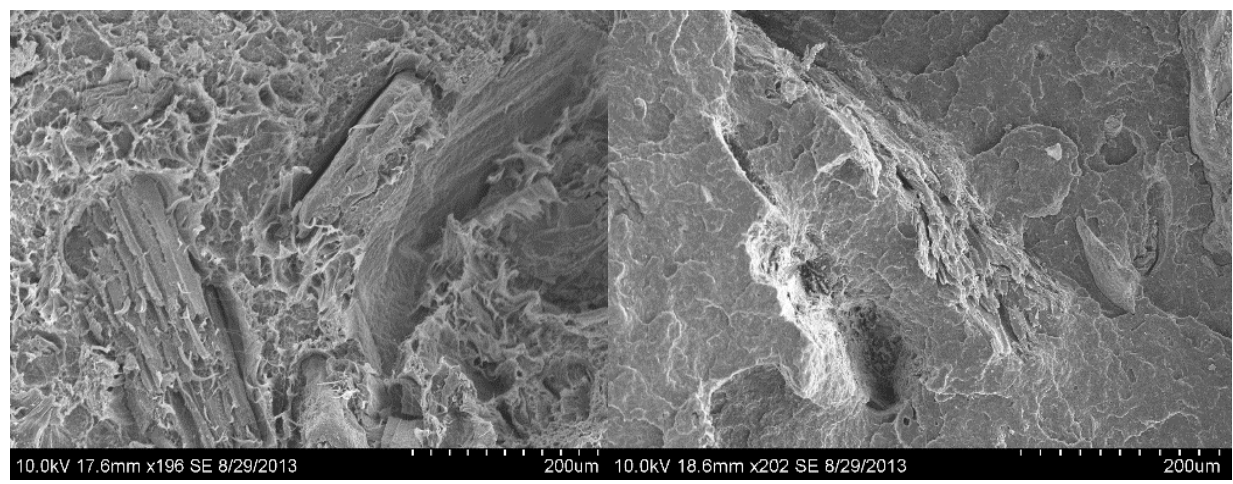

Figure 7. SEM images: left combination (2) 42,5\% PP, right combination (5) 63,75\% PP. (Both samples has the same materials factors).

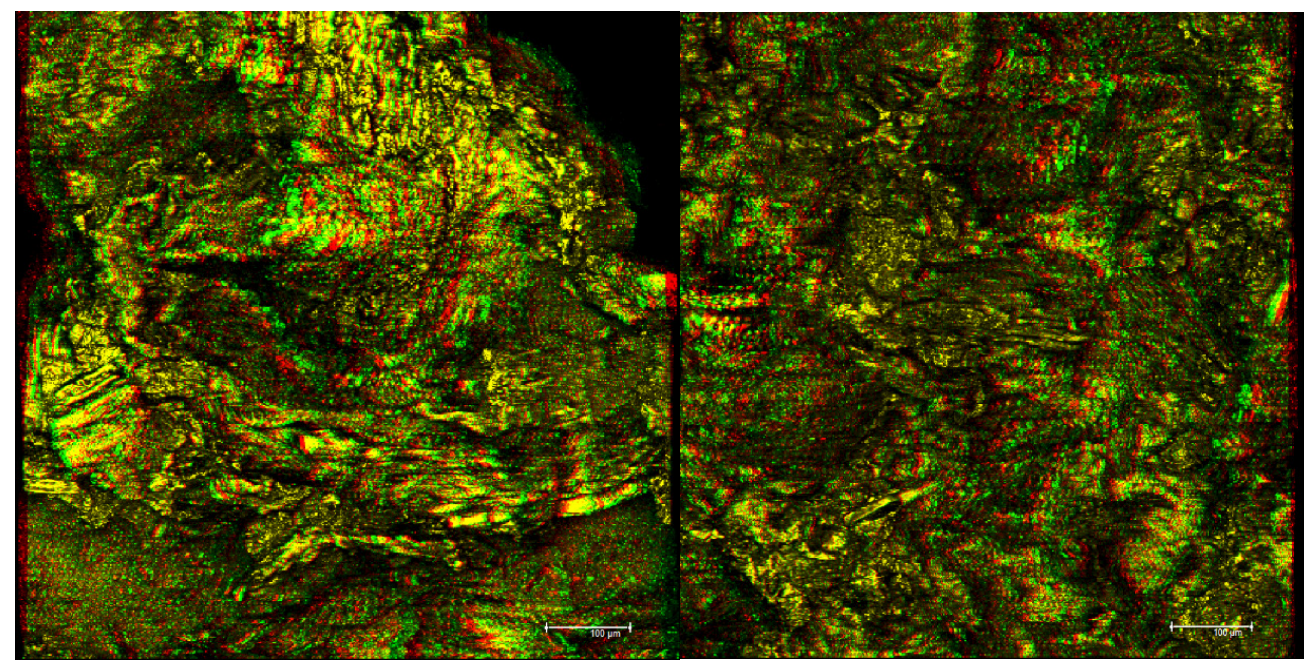

Figure 8. 3D-Confocal images: left combination (1) 30 mesh size, right combination (7) 80 mesh size (both samples have the same material compositions). 


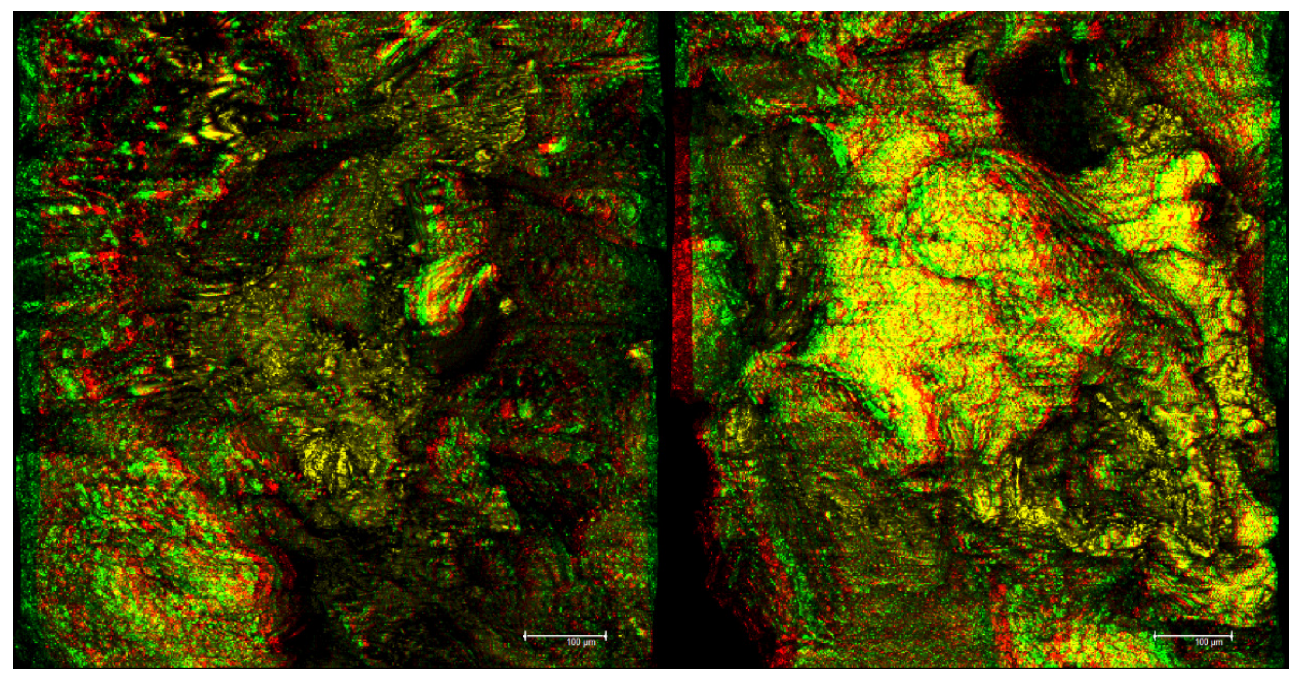

Figure 9. 3D-Confocal images of: left combination (2) 42,5\% PP, right combination (5) $63,75 \%$ PP (Both samples have the same materials factors).

\section{CONCLUSIONS}

From the analysis presented, it was found that highest levels of yield stress, ultimate tensile strength and breaking stress were reached by the proportion of 3 to 1 for the PP and wood fiber $(63,75 \%$ and $21,25 \%) ; 7,5 \%$ of fire retardant; $3,25 \%$ coupling agent and UV stabilizer and a mesh size of 80 .

Incidentally, the samples that showed the poorest mechanical properties were those with the highest level of Fire Retardant at $11,25 \%$. This suggests that even when Fire Retardant is a desirable ingredient for obvious reasons; it is in detriment of the integrity of mechanical properties of the final product. It was also found that 80 mesh grain sizes improve the properties better than 30 mesh size due to the better mixing and smaller surface area as well as lower internal stresses.

Material composition also affects the properties of the WPC, increasing the percentage of PP increases the yield stress, ultimate tensile strength and breaking stress. However, it reduces the modulus of elasticity.

\section{ACKNOWLEDGEMENTS}

The authors would like to thank the anonymous reviewers for their valuable suggestions and comments that greatly improved this article. 


\section{REFERENCES}

ASTM International. 2008. Standard Test for Determining the Charpy Impact Resistance of Notched Specimens of Plastics. ASTM D6110-06.

ASTM International. 2008. Standard Test Methods for Flexural Properties of Unreinforced and Reinforced Plastics and Electrical Insulating Materials. ASTM D790-03.

ASTM International. 2010. Standard Test Method for Tensile Properties of Plastics. ASTM 63809, ASTM D638-03.

Ayrilmis, N.; Buyuksari, U.; Dundar, T. 2010. Waste pine cones as a source of reinforcing fillers for thermoplastic composites. Journal of Applied Polymer Science 117(4): 2324-2330.

Dányádi, L.; Janecska, T.; Szabó, Z.; Nagy, G.; Móczó, J.; Pukánszky, B. 2007. Wood flour filled PP composites: compatibilization and adhesion. Composites Science and Technology 67(13): 2838-2846.

Dányádi, L.; Móczó, J.; Pukánszky, B. 2010. Effect of various surface modifications of wood flour on the properties of PP/wood composites. Composites Part A: Applied Science and Manufacturing 41(2): 199-206.

Fabiyi, J.S.; McDonald, A.G. 2010. Effect of wood species on property and weathering performance of wood plastic composites. Composites Part A: Applied Science and Manufacturing 41(10): 1434-1440.

García, M.; Hidalgo, J.; García-Jaca, J. 2009. Wood-plastics composites with better fire retardancy and durability performance. Composites Part A: Applied Science and Manufacturing 40(11): 1772-1776.

Georgopoulos, S.T.; Tarantili, P.A.; Avgerinos, E.; Andreopoulos, A.G.; Koukios, E.G. 2005. Thermoplastic polymers reinforced with fibrous agricultural residues. Polymer Degradation and Stability 90(2): 303-312.

Hietala, M.; Samuelsson, E.; Niinimäki, J.; Oksman, K. 2011. The effect of pre-softened wood chips on wood fibre aspect ratio and mechanical properties of wood-polymer composites. Composites Part A: Applied Science and Manufacturing 42(12): 2110-2116.

Ho, M.P.; Wang, H.; Lee, J.H.; Ho, C.K.; Lau, K. T.; Leng, J.; Hui, D. 2011. Critical factors on manufacturing processes of natural fibre composites. Composites Part B: Engineering 43(8): 35493562 .

Moreno, P.; Rodrigue, D.; Giroux, Y.; Ballerini, A.; Gacitua, W. 2013. Morphological and Mechanical Characterization of Recycled Thermoplastic Foams Reinforced with Wood Products. Maderas, Ciencia y Tecnología 15(1):1-16.

New Mexico Department of Agriculture (NMDA). 1994-2000. New Mexico Agricultural Statistics Service: Las Cruces, N.M.

Nourbakhsh, A.; Ashori, A. 2010. Wood plastic composites from agro-waste materials: Analysis of mechanical properties. Bioresource technology 101(7): 2525-2528.

Ozdemir, F.; Ayrilmis, N.; Kaymakci, A.; Kwon, J.H. 2014. Improving Dimensional Stability of Injection Molded Wood Plastic Composites Using Cold and Hot Water Extraction Methods. Maderas, Ciencia y Tecnología 16(3): 365-372. 
Reis, P.; Ferreira, J.; Silva, P. 2011. Mechanical behaviour of composites filled by agro-waste materials. Fibers and Polymers 12(2): 240-246.

Wang, H.; Chang, R.; Sheng, K.C. 2008. Impact response of bamboo-plastic composites with the properties of bamboo and polyvinylchloride (PVC). Journal of Bionic Engineering 5: 28-33.

Wechsler, A.; Hiziroglu, S. 2007. Some of the properties of wood-plastic composites. Building and Environment 42(7): 2637-2644.

Yeh, S.K.; Agarwal, S.; Gupta, R.K. 2009. Wood-plastic composites formulated with virgin and recycled ABS. Composites Science and Technology 69(13): 2225-2230. 